\title{
Synthesis and Properties of Polyimides from Bis[4-(Aminophenoxy)phenyl] Ether and Aromatic Dianhydrides Having Various Numbers of Phenylene Units
}

\author{
Atsushi Morikawa* and Tetsuya Toda \\ Department of Biomolecular Functional Engineering, Ibaraki University, \\ 4-12-1, Nakanarusawa, Hitachi, Ibaraki, 316-8511, Japan \\ *atsushi.morikawa.reg@vc.ibaraki.ac.jp
}

\begin{abstract}
Aromatic polyimides PI-3e-PMDA and PI-3e-m $(\mathbf{m}=\mathbf{0 - 4})$ with 3 ether linkages per monomer unit were prepared from bis[4-(4-aminophenoxy)phenyl] ether (1) and various tetracarboxylic dianhydrides, pyromellitic dianhydride (PMDA), 3,3'4,4'biphenyltertacarboxylic dianhydride (DA-0), 3,3"4,4"-p-terphenyltertacarboxylic dianhydride (DA-1), 3,3"'4,4"'-p-quarterphenyltertacarboxylic dianhydride (DA-2), 3,3"'"4,4"'"-p-quinquephenyltertacarboxylic dianhydride (DA-3), and 3,3"'" 4,4 "','-psexiphenyltertacarboxylic dianhydride (DA-4), by a conventional two-step procedure that included ring-opening polymerization in NMP and subsequent thermal cyclic dehydration. The polyimides were characterized by wide angle X-ray diffraction, differential scanning calorimetry (DSC), thermogravimetry (TG), and dynamic mechanical analysis (DMA), and compared on the basis of the number $(\mathbf{m})$ of phenylene units. PI-3e-PMDA and PI-3e-m $(\mathbf{m}=\mathbf{0 - 4})$ had glass transition temperatures $\left(T_{\mathrm{g}}\right)$ at $280^{\circ} \mathrm{C}$ and $210-230^{\circ} \mathrm{C}$, respectively, and $T_{\mathrm{g}}$ values were not dependent on $\mathbf{m}$. The storage modulus $\left(\boldsymbol{E}^{\prime}\right)$ of PI-3e-m decreased at about $200{ }^{\circ} \mathrm{C}$, after which a rubbery plateau resion was seen, followed by a further decrease at about $330{ }^{\circ} \mathrm{C}$. The DMA results for the annealed PI-3e-PMDA and PI-3e-m $(\mathbf{m}=\mathbf{0 - 4})$ were also compared and discussed on the basis of $\mathbf{m}$.

Keywords: Bis[4-(4-Aminophenoxy)phenyl] ether, 3,3"4,4"-pTerphenyltertacarboxylic dianhydride, 3,3"'4,4"'-p-Quarterphenyltertacarboxylic dianhydride, 3,3"' 4,4"'"-p-Quinquephenyltertacarboxylic dianhydride, 3,3"'"4,4"'"p-Sexiphenyltertacarboxylic dianhydride
\end{abstract}

\section{Introduction}

We previously synthesized dianhydrides DA-m having various numbers (m) of phenylene units, DA-2 [1], DA-3 [2] and DA-4 [3]. These were used to prepare aromatic polyimides containing $p$ quarterphenyl [1], $p$-quinquephenyl [2] and $p$ sexiphenyl [3] with various aromatic diamines [413]. The properties were compared with those of polyimides from DA-0 and DA-1, and discussed on the basis of the number $(\mathbf{m})$ of phenylene units [1416]. The $T_{\mathrm{g}}$ values were not dependent on $\mathbf{m}$, but depended on the structure of the diamine as reported in the literature [17]. The rotational barrier of the connecting group in the diamine moiety was reported to play a determining role in the value of
$T_{\mathrm{g}}$. In the temperature dependence of the storage modulus $\boldsymbol{E}^{\prime}$, a high-modulus glassy region was followed by a decrease in modulus at the $T_{\mathrm{g}}$, and rubbery plateau regions were observed above the $T_{\mathrm{g}}$ in the polyimides from DA-2, DA-3 and DA-4. The decrease in modulus was smaller with increasing $\mathbf{m}$. In polyimides from diamines with more ether linkage, unique DMA behavior was observed. The polyimides PI-5e-m $(\mathbf{m}=\mathbf{0 - 4})$ from bis $\{4-[4-(4-a m i n o p h e n o x y) p h e n o x y] p h e n y l\}$ ether with 5 ether linkages showed a two-step decrease in the storage modulus at $T_{\mathrm{g}}$ and the melting region, and exhibited adhesion when heated at the melting region [13]. The polyimides from DA-3 and 1,4-bis(4-amino-2-phenylphenoxy) 
benzene and 4,4'-bis(4-amino-2-phenylphenoxy) biphenyl having two ether linkages showed two rubbery plateau regions above the $T_{\mathrm{g}}$, and two $\tan \delta$ peak temperatures [9].

In this study, polyimides PI-3e-PMDA and PI3e-m $(\mathbf{m}=\mathbf{0 - 4})$ were synthesized from PMDA and DA-m $\quad(\mathbf{m}=\mathbf{0 - 4})$ and bis [4-(4aminophenoxy)phenyl] ether (1) with 3 ether linkages, and the properties were compared on the basis of the number of phenylene units $(\mathbf{m})$. The temperature dependence of the storage modulus for PI-3e-m $(\mathbf{m}=\mathbf{2 - 4})$ annealed at $320{ }^{\circ} \mathrm{C}$ exhibited unique behavior.

\section{Experimental}

2.1. Materials

Bis[4-(4-aminophenoxy)phenyl] ether (1) was prepared as previously reported [18]. PMDA and DA-0 were obtained commercially, and purified by sublimation under reduced pressure. DA-1 was supplied by Hitach Kasei Kogyo Co., Japan, and purified by recrystallization from acetic anhydride. DA-2 [1], DA-3 [2], and DA-4 [3] were prepared as previously reported. NMP was purified by vacuum distillation over calcium hydride.

\subsection{Polymer synthesis}

\subsubsection{PI-3e-PMDA}

In a three-necked flask, PMDA (0.436 g, 2.0 mmol) was added in one portion to a solution of $\mathbf{1}$ $(0.769 \mathrm{~g} 2.0 \mathrm{mmol})$ in $10 \mathrm{~mL}$ of NMP. The mixture was stirred at room temperature for $12 \mathrm{~h}$ under nitrogen. Part of the resulting viscous solution was poured into $200 \mathrm{~mL}$ of methanol. The precipitated polymer was filtered, washed with methanol and dried under vacuum. The NMP solution was cast onto a glass plate and the solvent was removed at $70{ }^{\circ} \mathrm{C}$. The thermal cyclodehydration of the polyamic acid was performed by successive heating at $100{ }^{\circ} \mathrm{C}$ for $1 \mathrm{~h}$, $200{ }^{\circ} \mathrm{C}$ for $1 \mathrm{~h}$, and finally $300^{\circ} \mathrm{C}$ for $1 \mathrm{~h}$ under vacuum. The IR spectrum (film) exhibited absorption bands at $1780 \mathrm{~cm}^{-1}$ and $1720 \mathrm{~cm}^{-1}(\mathrm{C}=\mathrm{O})$ and $1360 \mathrm{~cm}^{-1}(\mathrm{C}-\mathrm{N})$.

Anal. Calcd for $\mathrm{C}_{34} \mathrm{H}_{18} \mathrm{~N}_{2} \mathrm{O}_{7}: \mathrm{C}, 72.08 \% ; \mathrm{H}$, $3.20 \%$; N, 4.94\%. Found: C, 71.80\%; H, 2.98\%; N, $4.65 \%$.

\subsubsection{PI-3e-2}

In a three-necked flask, DA-2 (0.670 g, 1.5 $\mathrm{mmol}$ ) was added in one portion to a solution of $\mathbf{1}$ $(0.577 \mathrm{~g} 1.5 \mathrm{mmol})$ in $10 \mathrm{~mL}$ of NMP. The mixture was stirred at room temperature for $12 \mathrm{~h}$ under nitrogen. Part of the resulting viscous solution was poured into $200 \mathrm{~mL}$ of methanol. The precipitated polymer was filtered, washed with methanol and dried under vacuum. The NMP solution was cast onto a glass plate and the solvent was removed at $70{ }^{\circ} \mathrm{C}$. The thermal cyclodehydration of the polyamic acid was performed by successive heating at $100^{\circ} \mathrm{C}$ for $1 \mathrm{~h}$, $200{ }^{\circ} \mathrm{C}$ for $1 \mathrm{~h}$, and finally $300{ }^{\circ} \mathrm{C}$ for $1 \mathrm{~h}$ under vacuum. The IR spectrum (film) exhibited absorption bands at $1780 \mathrm{~cm}^{-1}$ and $1720 \mathrm{~cm}^{-1}(\mathrm{C}=\mathrm{O})$ and $1360 \mathrm{~cm}^{-1}(\mathrm{C}-\mathrm{N})$.

Anal. Calcd for $\mathrm{C}_{52} \mathrm{H}_{30} \mathrm{~N}_{2} \mathrm{O}_{7}: \mathrm{C}, 78.58 \% ; \mathrm{H}$, $3.80 \%$; N, 3.52\%. Found: C, $78.20 \%$; H, 3.35\%; N, $3.43 \%$.

\subsection{Measurements}

IR spectra were recorded on a Shimadzu spectrometer IR 435. Reflection mode wide-angle $\mathrm{X}$-ray diffraction (WAXD) measurements were performed at room temperature in the range of $2 \theta=$ $5-60^{\circ}$ with a sampling step of $0.1^{\circ}$ and a scan rate $10^{\circ} \min ^{-1}$ on a Rigaku RAD-B system with a radiation source of $\mathrm{CuK \alpha}$. For differential scanning calorimetry (DSC) and thermogravimetry (TG), a Shimadzu DSC-60 and Rigaku thermal analysis station TG 8110 were used, respectively. Dynamin mechanical analysis (DMA) at $1.0 \mathrm{~Hz}$ and thermomechanical analysis were performed with the Advanced Rheometric Expansion System at $5{ }^{\circ} \mathrm{C} \min ^{-1}$.

\section{Results and discussion}

\subsection{Polymer synthesis}

Aromatic polyimides were synthesized by the two-step procedure involving the ring-opening polymerization of diamine $\mathbf{1}$ to tetracarboxylic dianhydride $[$ PMDA, DA-m $(\mathbf{m}=\mathbf{0 - 4})]$ and subsequent thermal cyclodehydration as shown in Scheme 1.

In the first step, ring-opening polymerizations were carried out in NMP at room temperature, leading to the formation polyamic acids [PAA-3ePMDA, PAA-3e-m $(\mathbf{m}=\mathbf{0 - 4})]$ having inherent viscosities of $0.87-1.31 \mathrm{dLg}^{-1}$ in NMP (Table 1). In the second step, the thermal conversion of the polyamic acids was performed by heating the precursor polymers in the form of films successively at 100 for $1 \mathrm{~h}, 200$ for $1 \mathrm{~h}$, and finally 300 for $1 \mathrm{~h}$ under vacuum. These polyimides produced tough films.

The formation of the polyimides was confirmed by the appearance of IR absorption bands at about 


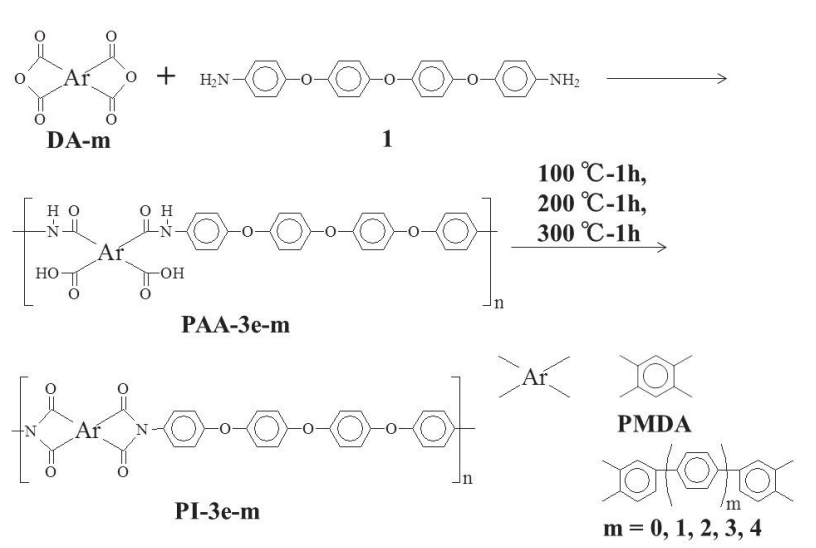

Scheme 1. Synthesis of polyimides PI-3e-PMDA and PI-3e-m $(m=0-4)$.

Table 1. Synthesis of PAA-3e-PMDA and PAA-3e-m $(\mathbf{m}=\mathbf{0 - 4})$.

\begin{tabular}{cccc}
\hline Dianhydride & $\begin{array}{c}\text { Polyamic } \\
\text { acid }\end{array}$ & Yield /\% & $\begin{array}{c}\eta_{\text {inh }} \\
/ \mathrm{dLg}^{-1} \mathrm{c}\end{array}$ \\
\hline PMDA & $\begin{array}{c}\text { PAA-3e- } \\
\text { PMDA }^{\text {a }}\end{array}$ & 95 & 1.20 \\
$\mathrm{~m}=0$ & PAA-3e-0 $^{\text {a }}$ & 96 & 1.31 \\
$\mathrm{~m}=1$ & PAA-3e-1 $^{\text {a }}$ & 96 & 0.96 \\
$\mathrm{~m}=2$ & PAA-3e-2 $^{\text {b }}$ & 94 & 0.87 \\
$\mathrm{~m}=3$ & PAA-3e-3 $^{\text {b }}$ & 96 & 1.08 \\
$\mathrm{~m}=4$ & PAA-3e-4 $^{\text {b }}$ & 96 & 1.22 \\
\hline
\end{tabular}

${ }^{a}$ Polymerization was carried out with $2.0 \mathrm{mmol}$ of each monomer in $10 \mathrm{~mL} \mathrm{NMP} \mathrm{at} \mathrm{room} \mathrm{temperature} \mathrm{for} 12 \mathrm{~h}$ under nitrogen.

b Polymerization was carried out with $1.5 \mathrm{mmol}$ of each monomer in $10 \mathrm{~mL} \mathrm{NMP}$ at room temperature for $12 \mathrm{~h}$ under nitrogen.

${ }^{\mathrm{c}}$ Measured at $0.5 \mathrm{~g} \mathrm{dL}^{-1}$ in NMP at $30^{\circ} \mathrm{C}$.
$1780 \mathrm{~cm}^{-1}, 1720 \mathrm{~cm}^{-1}$ and $1360 \mathrm{~cm}^{-1}$, characteristic of an imide group. Elemental analysis values were in close agreement with the calculated values, also supporting polyimide formation.

\subsection{Polymer properties}

The thermal properties of the polyimides were evaluated by DSC and TG, and transition temperatures and $10 \%$ weight loss temperature $\left(T_{10}\right)$ are shown in Table 2. No polyimides exhibited a weight loss below $470{ }^{\circ} \mathrm{C}$ in air or nitrogen. $T_{10}$ values in air and nitrogen were in the range of 535$568{ }^{\circ} \mathrm{C}$ and $585-600{ }^{\circ} \mathrm{C}$, respectively, and were slightly higher with increasing $\mathbf{m}$. In DSC measurements (Fig. 1), PI-3e-PMDA showed $T_{\mathrm{g}}$ at $280{ }^{\circ} \mathrm{C}$, while PI-3e-m $(\mathbf{m}=\mathbf{0 - 4})$ did not show $T_{\mathrm{g}}$ clearly. PI-3e-0 and PI-3e-1 showed exothermic crystallization peaks at around $270{ }^{\circ} \mathrm{C}$ followed by endothermic peaks at around $370{ }^{\circ} \mathrm{C}$. PI-3e-2 and PI-3e-3 clearly showed endothermic peals at around $410{ }^{\circ} \mathrm{C}$ due to their higher crystallinity. In the WAXD patterns for these polyimides, PI-3e-0, PI3e-1, PI-3e-3, PI-3e-4 showed slightly intense diffraction peaks at around $2 \theta=20^{\circ}$, which were assigned to crystalline polymers (Fig. 2 (a)). PI3e-PMDA and PI-3e-m $(\mathbf{m}=\mathbf{0 - 4})$ were insoluble in organic solvents even upon heating similar to PI-5ePMDA and PI-5e-m $(\mathbf{m}=\mathbf{0 - 4})$ [13].

The dynamic mechanical properties of these polyimides were also compared. The $T_{\mathrm{g}}$ values were observed as the $\tan \delta$ peak temperature (Fig. 3).

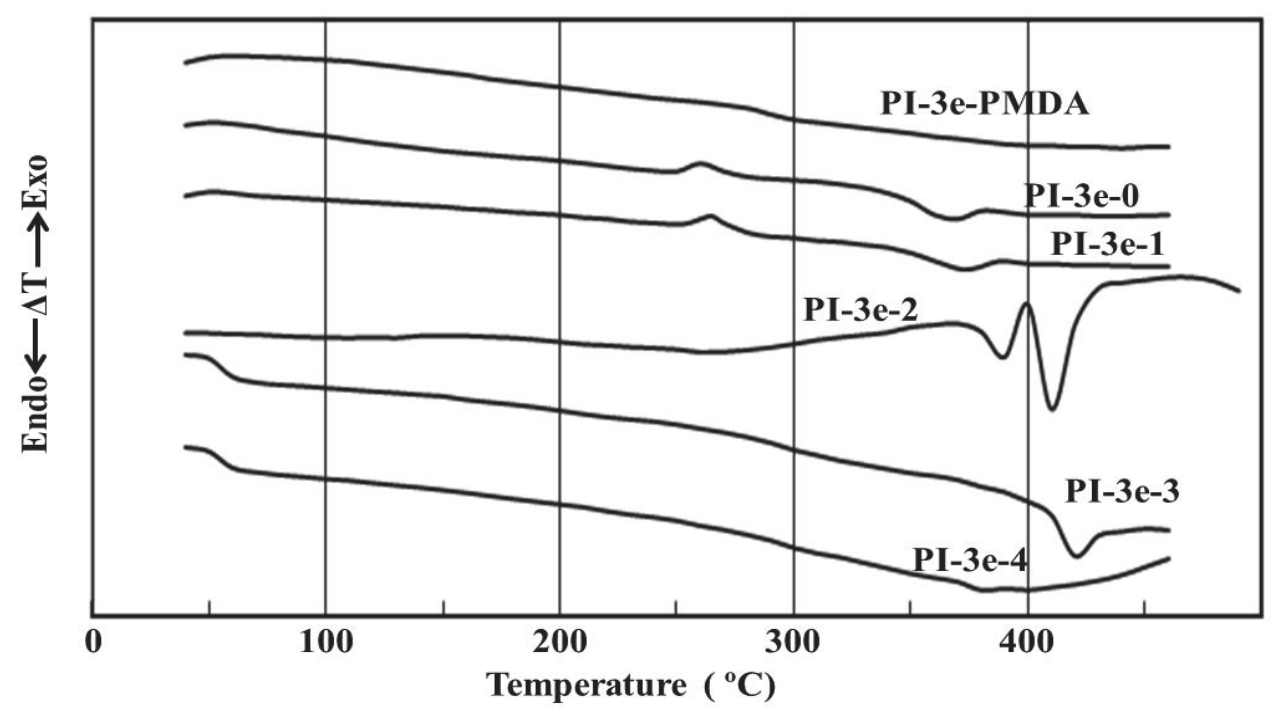

Fig. 1. DSC curves for PI-3e-PMDA and PI-3e-m $(\mathbf{m}=\mathbf{0 - 4})$. 
Table 2. Thermal properties of PI-3e-PMDA and PI-3e-m $(\mathbf{m}=\mathbf{0 - 4})$.

\begin{tabular}{ccccccc}
\hline Polyimide & $T_{\mathrm{g}} /{ }^{\circ} \mathrm{C}^{\mathrm{a}}$ & $T_{\mathrm{g}} /{ }^{\circ} \mathrm{C}^{\mathrm{b}}$ & $T_{\mathrm{m}} /{ }^{\circ} \mathrm{C}^{\mathrm{b}}$ & $T_{10} /{ }^{\circ} \mathrm{C}^{\mathrm{c}}$ & $T_{10} /{ }^{\circ} \mathrm{C}^{\mathrm{d}}$ & $T_{\mathrm{g}} /{ }^{\circ} \mathrm{C}^{\mathrm{e}}$ \\
\hline PI-3e-PMDA & 280 & $--\mathrm{f}^{\mathrm{f}}$ & $--{ }^{\mathrm{f}}$ & 535 & 585 & 285 \\
PI-3e-0 & 230 & $250-280$ & $320-380$ & 545 & 590 & 230 \\
PI-3e-1 & 230 & $250-290$ & $340-385$ & 550 & 590 & 230 \\
PI-3e-2 & 210 & $-{ }^{\mathrm{f}}$ & $370-400$ & 560 & 595 & 340 \\
& & & $400-430$ & & & \\
PI-3e-3 & 220 & $--\mathrm{f}$ & $390-440$ & 568 & 600 & 230 \\
PI-3e-4 & 210 & $--{ }^{\mathrm{f}}$ & $370-430$ & 560 & 600 & 240 \\
\hline
\end{tabular}

${ }^{\mathrm{a}}$ Tan $\delta$ peak temperature was recorded by DMA at a heating rate $5{ }^{\circ} \mathrm{C} \mathrm{min}^{-1}$.

${ }^{\mathrm{b}}$ Determined by DSC in nitrogen at a heating rate of $10^{\circ} \mathrm{C} \mathrm{min}^{-1}$.

${ }^{\mathrm{c}}$ Temperature at which $10 \%$ weight loss was recorded by TG at a heating rate of $10^{\circ} \mathrm{C} \mathrm{min}^{-1}$ in air.

${ }^{\mathrm{d}}$ Temperature at which $10 \%$ weight loss was recorded by TG at a heating rate of $10{ }^{\circ} \mathrm{C} \mathrm{min}^{-1}$ in nitrogen.

${ }^{\mathrm{e}}$ Tan $\delta$ peak temperature of annealed polyimide film was recorded by DMA at a heating rate of $5^{\circ} \mathrm{C} \mathrm{min}^{-1}$.

${ }^{\mathrm{f}}$ Not detected by DSC.

(a)

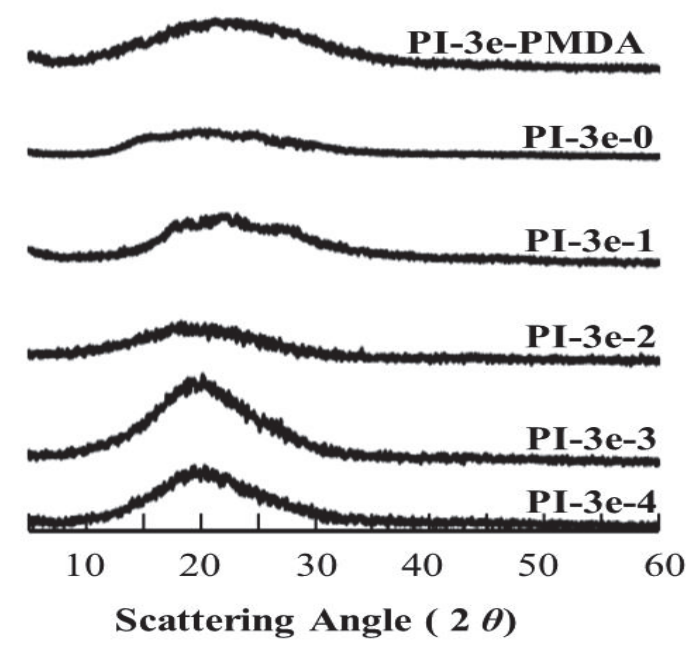

(b)

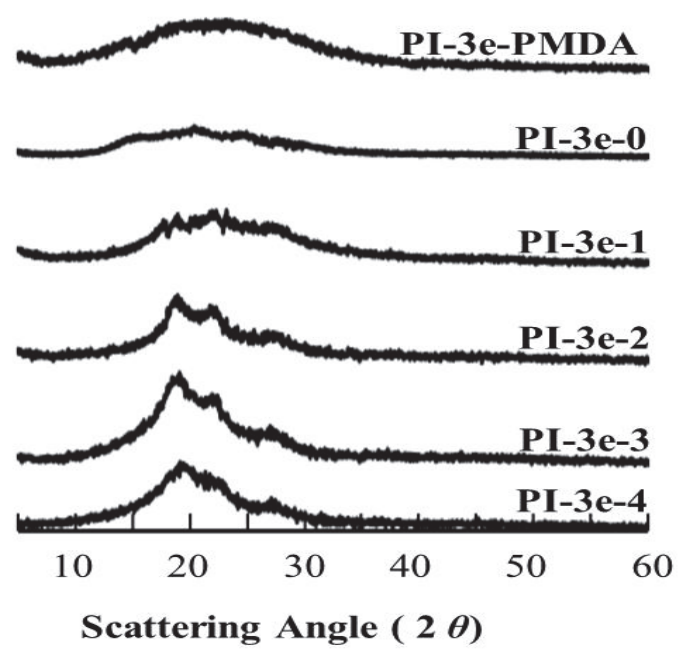

Fig. 2. X-ray diffraction patterns for PI-3e-PMDA and PI-3e-m $(\mathbf{m}=\mathbf{0 - 4})$ before annealing (a) and after annealing (b).

The $T_{\mathrm{g}}$ values for PI-3e-PMDA and PI-3e-0, PI-3e1, PI-3e-2, PI-3e-3 and PI-3e-4 were $280{ }^{\circ} \mathrm{C}$, $230{ }^{\circ} \mathrm{C}, 230{ }^{\circ} \mathrm{C}, 210{ }^{\circ} \mathrm{C}, 220{ }^{\circ} \mathrm{C}$, and $210{ }^{\circ} \mathrm{C}$, respectively (Table 1), which were slightly higher than those for PI-5e-PMDA and PI-5e-m $(\mathbf{m}=\mathbf{0 -}$ 4) [13], and the $T_{\mathrm{g}}$ values were not dependent on $\mathbf{m}$. The value for PI-3e-PMDA was the highest due to intermolecular charge transfer [19], similar to the case for previously reported polyimides from dianhydrides having various numbers of phenylene units [1-16].

The temperature-dependent storage modulus, $\boldsymbol{E}^{\prime}$, for the polyimides is described as follows. A high modulus glassy region was followed by a decrease in the modulus at $T_{\mathrm{g}}$. The $\boldsymbol{E}$ ' value for amorphous PI-3e-PMDA decreased at around $350{ }^{\circ} \mathrm{C}$ to about

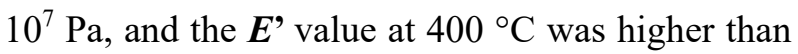
that for PI-5e-PMDA due to fewer ether linkages [13]. The $\boldsymbol{E}$ ' value for PI-3e-m $(\mathbf{m}=\mathbf{0 - 4})$ decreased at a $T_{\mathrm{g}}$ of $200{ }^{\circ} \mathrm{C}$, after which a rubbery plateau region was seen, followed by an additional decrease at about $330^{\circ} \mathrm{C}$. The $\boldsymbol{E}$ ' value for PI-3e-m $(\mathbf{m}=\mathbf{0 - 4})$ was about $10^{4} \mathrm{~Pa}$ at $400{ }^{\circ} \mathrm{C}$, which was lower than that for PI-5e-m $(\mathbf{m}=\mathbf{0 - 4})$ despite having fewer ether linkages. However, PI-3e-m $(\mathbf{m}=\mathbf{0 - 4})$ did not show adhesion properties when heated at $400{ }^{\circ} \mathrm{C}$ as did PI-5e-PMDA and PI-5e-m $(\mathbf{m}=\mathbf{0 - 4})$ [13]. The decrease in $\boldsymbol{E}$ ' was thought to be due to melting and was accompanied by an endothermic process in the DSC measurements.

In the DSC measurement, PI-3e-0 and PI-3e-1 showed exothermic peaks at $250-280{ }^{\circ} \mathrm{C}$ and 250 $290{ }^{\circ} \mathrm{C}$, respectively, and ordered structures such as crystals were thought to be formed above $T_{\mathrm{g}}$. PI3e-0 and PI-3e-1 films were annealed at $300{ }^{\circ} \mathrm{C}$ for 30 min. PI-3e-m $(\mathbf{m}=\mathbf{2}-\mathbf{4})$ did not show any clear exothermic peaks in DSC measurements, but were annealed at $320^{\circ} \mathrm{C}$, a temperature at which $\boldsymbol{E}$ ' did 

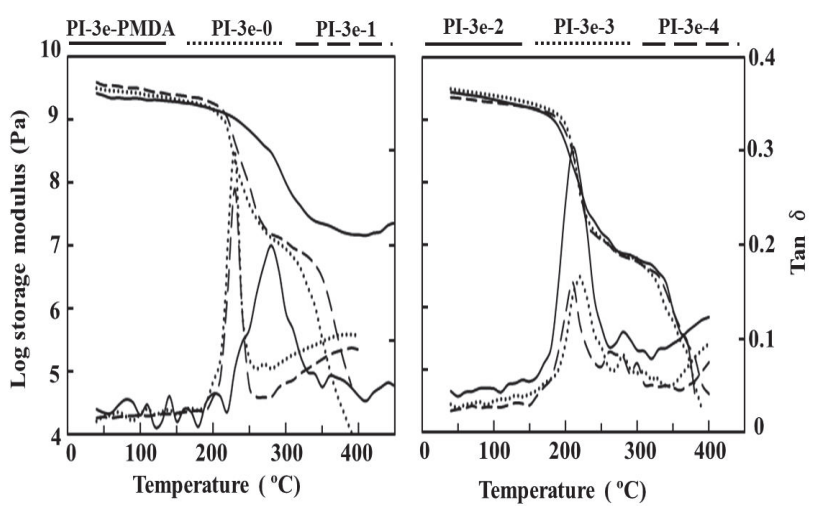

Fig. 3. Dynamic mechanical properties of PI-3e-PMDA and PI-3e-m $(\mathbf{m}=\mathbf{0 - 4})$.

not show additional decreases, for $30 \mathrm{~min}$. PI-3ePMDA was also annealed at $320^{\circ} \mathrm{C}$. The DMA properties of the annealed polyimide films are shown in Fig. 4. PI-3e-m $(\mathbf{m}=\mathbf{0 - 4})$ showed higher $\boldsymbol{E}^{\prime}$ values in the rubbery plateau region above $T_{\mathrm{g}}$ than those before annealing. The $\boldsymbol{E}$, value for PI-3e-2 was higher than those for PI-3e-3 and PI$\mathbf{3 e - 4}$, in contrast to the previously reported polyimides [1-16] from dianhydrides having various numbers of phenylene units, for which the $\boldsymbol{E}$ ' value was higher with increasing phenylene units (m). PI-3e-m $(\mathbf{m}=\mathbf{2}-\mathbf{4})$ did not show an additional decrease in $\boldsymbol{E}$, at about $330{ }^{\circ} \mathrm{C}$, which was observed before annealing. The $T_{\mathrm{g}}$ values (the tan $\delta$ peak temperatures) for PI-3e-m $(\mathbf{m}=\mathbf{2 - 4})$ were higher than those before annealing. In particular, that for PI-3e-2 was $340{ }^{\circ} \mathrm{C}, 130{ }^{\circ} \mathrm{C}$ higher, and higher than those of PI-3e-m $(\mathbf{m}=\mathbf{3}, \mathbf{4})$. The increment of $\boldsymbol{E}^{\prime}$ value in the plateau region for PI-3e-m $(\mathbf{m}=\mathbf{0 - 4})$ and the higher $T_{\mathrm{g}}$ values for PI3e-m $(\mathbf{m}=\mathbf{2 - 4})$ were thought to be due to the development of ordered structures. The WAXD patterns for the annealed PI-3e-m $(\mathbf{m}=\mathbf{0 - 4})$ were sharper, and the peak intensity for the annealed PI3e-2 greatly increased (Fig. 2-(b)). The disappearance of the decrease in $E$ ' observed for the annealed PI-3e-m $(\mathbf{m}=\mathbf{2 - 4})$ was regarded as a shift of the melting region to above $450^{\circ} \mathrm{C}$. Such a shift due to the development of a crystalline structure was observed for poly[(3,3'-dioxyphenyl)diphenylene pyromellitimide] [20].

Figure 5 shows the thermochemical analysis results for annealed PI-3e-PMDA and PI-3e-m (m $=0-4)$. The elongations due to the glass transition for PI-3e-m $(\mathbf{m}=\mathbf{2 - 4})$ were much shower than those for PI-3e-m (m $=\mathbf{0 - 1})$, and PI-3e-2 barely elongated. Remarkable elongations at about $330{ }^{\circ} \mathrm{C}$ for PI-3e-m $(\mathbf{m}=\mathbf{2 - 4})$ were not observed,
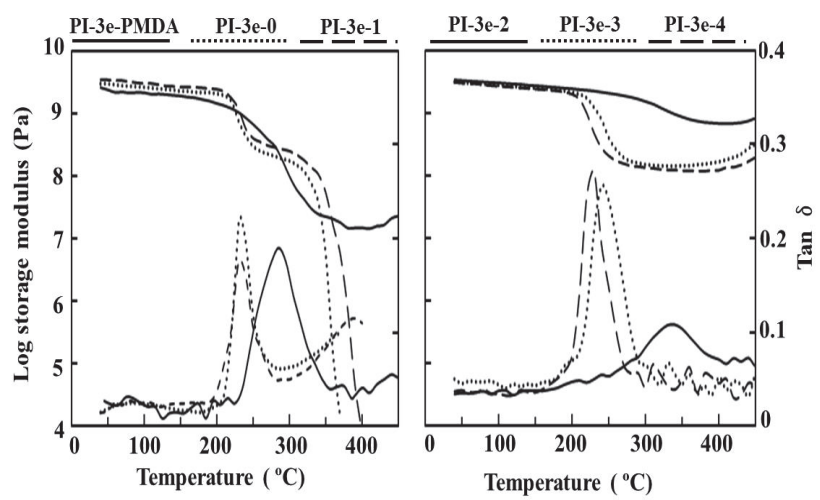

Fig. 4. Dynamic mechanical properties of annealed PI3e-PMDA and PI-3e-m $(\mathbf{m}=\mathbf{0 - 4})$.

which reflected the DMA results. The elongations for PI-3e-m $(\mathbf{m}=\mathbf{2 - 4})$ in the temperature range 50$450{ }^{\circ} \mathrm{C}$ were about $0.7 \%$, and as short as those for the polyimides [16] from DA-m $(\mathbf{m}=\mathbf{1 - 3})$ and $p$ phenylenediamine, even though PI-3e-m $(\mathbf{m}=\mathbf{2 - 4})$ had three flexible ether linkages in the repeating unit.

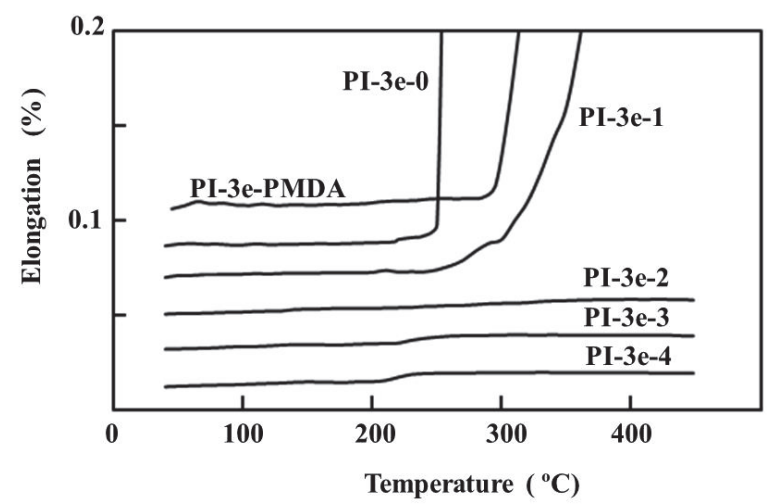

Fig. 5. Thermomechanical analysis of annealed PI-3ePMDA and PI-3e-m $(m=0-4)$.

\section{Conclusion}

Polyimides PI-3e-PMDA and PI-3e-m $(\mathbf{m}=\mathbf{0 - 4})$ were synthesized from bis [4-(4aminophenoxy)phenyl] ether and aromatic dianhydrides having various numbers (m) of phenylene units, and their properties were compared on the basis of the number (m) of phenylene units in the dianhydrides. The $T_{\mathrm{g}}$ values (the $\tan \delta$ peak temperatures) for PI-3e-PMDA and PI-3e-m ( $\mathbf{m}=$ 0-4) were $280{ }^{\circ} \mathrm{C}$ and $210-230{ }^{\circ} \mathrm{C}$, respectively. The storage modulus $\left(\boldsymbol{E}^{\prime}\right)$ for PI-3e-m $(\mathbf{m}=\mathbf{0}-\mathbf{4})$ decreased at about $200{ }^{\circ} \mathrm{C}$, after which a rubbery plateau region was seen, followed by a further decrease at about $330{ }^{\circ} \mathrm{C}$. After the polyimides were annealed, the $\boldsymbol{E}^{\prime}$ values for the plateau region 
were higher, PI-3e-m $(\mathbf{m}=\mathbf{2}-\mathbf{4})$ did not show any further decrease in $\boldsymbol{E}^{\prime}$ at about $330{ }^{\circ} \mathrm{C}$, and the $T_{\mathrm{g}}$ values of PI-3e-m $(\mathbf{m}=\mathbf{2 - 4})$ were higher, with PI3e-2 being $340^{\circ} \mathrm{C}\left(130^{\circ} \mathrm{C}\right.$ higher $)$.

\section{References}

1. A. Morikawa, Polym. J., 32 (2000) 275.

2. A. Morikawa and Y. Hosoya, Polym. J., 34 (2002) 544.

3. A. Morikawa and K. Ono, Polym. J., 32 (2000) 948.

4. A. Morikawa, T. Furukawa, and Y. Moriyama, Polym. J., 37 (2005) 759.

5. A. Morikawa, T. Furukawa, and Y. Moriyama, High Perform. Polym., 18 (2006) 593.

6. T. Okabe and A. Morikawa, High Perform. Polym., 20 (2008) 53.

7. A. Satoh and A. Morikawa, High Perform. Polym., 22 (2010) 412.

8. T. Okabe and A. Morikawa, High Perform. Polym., 22 (2010) 799.

9. A. Morikawa, F. Miyata, and J. Nishimura, High Perform. Polym., 24 (2012) 783.

10. A. Morikawa, S. Nabeshima, A. Satoh, and Y. Moriyama, J. Photopolym. Sci. Technol., 26 (2013) 367.
11. S. Nabeshima and A. Morikawa, High Perform. Polym., 27 (2015) 772.

12. A. Morikawa, C. Karube, and Y. Sakaki, High Perform. Polym., 28 (2016) 1201.

13. A. Umezawa and A. Morikawa, J. Photopolym. Sci. Technol., 32 (2019) 489.

14. A. Morikawa and K. Ono, High. Perform. Polym., 13 (2001) S73.

15. A. Morikawa, "High Performance Polymers and Engineered Plastics", V. Mittal, Ed., Wiley, Salem, 7 (2011) 205.

16. Y. Hosoya and A. Morikawa, J. Photopolym. Sci. Technol., 32 (2019) 495.

17. J. de Abajo and J. G. de la Campa, "Processable Aromatic Polyimides", in "Advances in Polymer Science", 140 (1999) 23, SpringerVerlag Berlin Heidelberg.

18. T. J. Dingemans, E. Mendes, J. J. Hinkley, E. S. Weiser, and T. L. StClar, Macromolecules, 41 (2008) 2474.

19. S. Ando, T. Matsuura, and S. Sakaki, Polym. J., 29 (1997) 69.

20. S. P. Ma, S. Yuasa, M. Tsuji, K. Sakurai, and T. Takahashi, Kobunshi Ronbunshu, 51 (1994) 329 (in Japanese). 